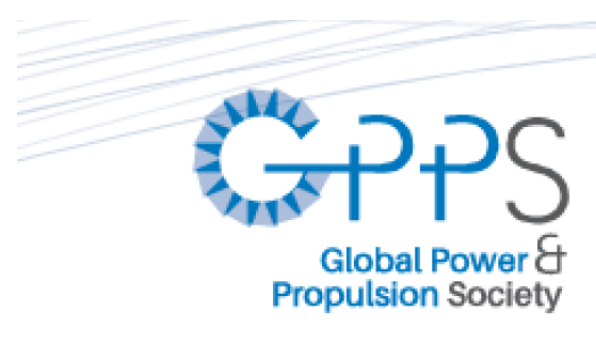

Proceedings of Global Power and Propulsion Society

ISSN-Nr: 2504-4400

Beijing Conference 2019

$16^{\text {th }}-18^{\text {th }}$ September, 2019

www.gpps.global

GPPS-BJ-2019-0191

\title{
EXTINCTION AND RE-IGNITION PREDICTIONS USING EDDY DISSIPATION CONCEPT AND FLAMELET GENERATED MANIFOLD MODELS FOR A PREMIXED PILOTED TURBULENT JET BURNER
}

\author{
Hossam A. Elasrag ${ }^{\dagger},{ }^{*}$ Ishan Verma ${ }^{\S}$, Chitral Naik ${ }^{\dagger}$, Shaoping $\mathrm{Li}^{\dagger}$, and Ellen Meeks ${ }^{\dagger}$ \\ $\dagger$ ANSYS Inc., San Diego, CA, USA \\ $¥$ ANSYS Inc., Lebanon, NH, USA \\ $\S$ ANSYS Inc., Hinjewadi Pune, , India
}

\begin{abstract}
The Sydney piloted premixed jet burner (PPJB) experiments are numerically simulated to assess the flamelet generated manifold (FGM) model's ability to predict finite-rate and turbulence/chemistry-interaction effects under low Damköhler number. The results are also compared and assessed with the finite rate eddy-dissipation concept (EDC) model. A reduced $\mathrm{CH}_{4} /$ air mechanism of 71 species, that considers low-and hightemperature chemistry, is derived from the Model Fuel Library (MFL) and compared with the master MFL mechanism. The same mechanism is used for chemistry closure for both FGM and EDC models. The PPJB simulations are found to be sensitive to the inflow profiles and different power-law profiles are adopted for different centerline jet bulk velocity setups. An overall good match with the experimental data is observed for the non-reactive flow cases, with general under-prediction for the turbulent kinetic energy (TKE). For the PM150 flame conditions presented here, the FGM showed reasonable prediction of the temperature and major species, with under-prediction for $\mathrm{OH}$ and over-prediction
\end{abstract}

\footnotetext{
${ }^{*}$ Corresponding author, Software Developer, hossam.elasrag @ ansys.com
}

\footnotetext{
This work is licensed under Attribution-NonCommercial$\begin{array}{llll}\text { NoDerivatives } & 4.0 \quad \text { International (CC-BY-NC-ND). See: }\end{array}$ https://creativecommons.org/licenses/by-nc-nd/4.0/legalcode
}

for temperature peak, $\mathrm{CO}_{2}$, and $\mathrm{CO}$ mass fractions. The FGM was able to capture the flame necking downstream of the nozzle but not the flame's extinction and re-ignition. The impact of the EDC chemical reaction rates time and length scales are shown. The EDC model was found to capture the PM150 flame necking as well as re-ignition downstream with the smaller time-scale factor. With a higher reaction-time-scale constant, the necking behavior was captured but the temperature was over-predicted with no extinction or re-ignition observed.

\section{INTRODUCTION}

To reduce emissions, modern gas turbine engine designs often rely on burning a lean premixed mixture either fully or in a staged manner [1]. Examples of such designs are the lean premixed pre-vaporized (LPP), Lean direct injection designs (LDIs), dry low NOx (DLN) GE-combustor, and GE's Twin Annular Premixed Swirl (TAPS) combustor [2]. Burning under lean conditions, reduces emissions significantly with the adverse challenge of possible dynamic instabilities [3]. Target emission levels [4] for stationary gas turbine engines are set to be regulated to around 25ppm NOx for liquid fuels and for $<10 \mathrm{ppm}$ NOx and $10 \mathrm{ppm}$ $\mathrm{CO}$ for natural gas fuels. For aero-engines, the regulations are even more stringent and single-digit ppm emission levels might be targeted.

The naturally high turbulent conditions of the aforemen- 
tioned designs can thicken the flame's reaction zone by the impact of smaller sized vortices. The local vortices inside the reaction zone can induce high mass and heat transfer that can result in local or global extinction [5] and re-ignition [6]. Premixed flames can undergo local flame extinction due to high flame turbulence interactions in the premixed distributed flame front regime that is characterized by low Damköhler number (Da) and high Karlovitz number (Ka). The Da number is defined as the ratio of the characteristic large eddy turbulence to characteristic chemical time scales (i.e. $\frac{\tau_{t}}{\tau_{c}}$ ) and the Ka number is defined as the ratio of the characteristic chemical time scales to the smallest turbulent time scale (i.e. $\frac{\tau_{c}}{\tau_{\eta}}$ ) [7]. In this regime the flame can be also termed as a thickened flame front.

Modeling under such conditions is not ideal for flamelet models [8] as the assumptions of thin reaction zone and fast chemistry (i.e. high Da number) are violated [9]. Flamelet models, however, can predict weak finite-rate chemistry effects $[5,10,11]$ with a reasonable success. Finite rate chemistry based models on the other hand will be ideal to predict high turbulence-chemistry interaction for this type of simulation. Most gas turbine engines, especially aero-engines, uses higher hydro-carbon fuels and it will be costly to use finite-rate based models to simulate a full gas turbine combustor. Flamelet models, on the other hand are efficient in terms of computational cost but limited by their assumptions of fast chemistry. A few flamelet models' such as the flamelet progress variable (FPV) [12] and the flamelet generated manifold model (FGM) $[13,14]$ introduce a progress variable equation that tracks the reaction progress through a finite-rate source term. Performance of such models under the current low $\mathrm{Da}$ and high Ka numbers, where strong finite-rate effects are expected, are yet to be assessed.

The piloted premixed jet burner (PPJB), used in the current work, is designed by Dunn and Masri [6] to investigate finite rate chemistry effects in highly turbulent lean premixed combustion. The setup has the advantage of isolating the finite-rate chemistry/turbulence interactions without the complications of swirl and spray injection. The setup has measurements for five flames with different central jet velocity that ranges from $50 \mathrm{~m} / \mathrm{s}$ to $200 \mathrm{~m} / \mathrm{s}$. The flames are labeled as PM-xxx, where $\mathbf{x x x}$ is the central jet velocity. A few attempts have been published to simulate the current burner. Chen and Ihme [11] performed large eddy simulation (LES) for the burner using the FPV approach; they reported that the model was capable of predicting flow-field, temperature, and major species profiles. The flowfield was also found to be sensitive to the scalar inflow composition, and scalar boundary conditions. Over-prediction for the fuel-consumption for PM1-150 flame (discussed in the next section) was also observed. The probability density function was also used by Dunn et al. [9] to simulate the same burner setup. The numerical predictions using a particle-based PDF model was found to be able to predict the mean temperature field by vary- ing the model mixing constant. Rowiniski and Pope [15] simulated the burner using the joint velocity-turbulence frequencycomposition PDF method. They found that at high central jet velocity setups (i.e. PM1-150 and PM1-200) the simulations show severe over-predictions for products and temperature with underprediction of fuel and oxidizer.

In the current work, the piloted premixed jet burner (PPJB) experimental setup [11] is used to test the ability of the eddy dissipation concept (EDC) and the FGM model to predict the finite-rate chemistry effect in high-shear turbulent flow. The two models are compared and assessed with the measurements. The turbulent chemistry interactions are modeled with the EDC [16] combined with In-Situ Adaptive Tabulation (ISAT) [17] and chemistry agglomeration to reduce the computational cost. A mechanism of $\mathbf{7 1}$ species is reduced from the Model Fuel Library (MFL) [18] database to model chemistry. The mechanism includes the low-temperature chemistry effects. The impact of local time and length scale modeling is also shown for the EDC model. The paper is organized as follow. First we briefly describe the EDC and the FGM models components. Then the burner numerical and experimental setup are shown. Next the cold flow and reactive flow results are shown and discussed. Finally, the paper concludes with a summary of the paper results.

\section{Eddy Dissipation Concept (EDC) model}

Here we describe briefly the EDC model. More details can be found in the ANSYS-Fluent theory guide [19]. For $N$ chemical species, ANSYS fluent solves $N-1$ species transport equation. For a species $i$ the transport equation can be written as :

$$
\frac{\partial\left(\rho Y_{i}\right)}{\partial t}+\nabla \cdot\left(\rho \vec{v} Y_{i}\right)=-\nabla \cdot \vec{J}_{i}+R_{i}+S_{i}
$$

where $Y_{i}$ is the mass fraction of species $i, \vec{v}$ is the velocity vector, $\vec{J}_{i}=-\rho\left(D_{i, m}+\frac{\mu_{t}}{S c_{t}}\right) \nabla Y_{i}-D_{T, i} \frac{\nabla T}{T}$ is the diffusion flux for species $i$, and $R_{i}$ is the net rate of production of species $i$ by chemical reaction, and $S_{i}$ is the rate of creation of species $i$ from the dispersed phase. In the $J_{i}$ equation, $D_{i, m}$ is the mass diffusion coefficient for species $i$ in the mixture, and $D_{T, i}$ is the thermal (soret) diffusion coefficient.

The EDC model assumes that reactions occur within small turbulent structures, called the fine scales, as in a constantpressure reactor. The reactor initial conditions are taken to be the current composition and temperature in the cell. The reaction is assumed to occur in the fine scales, within the sub-filter level. Where the fine-scale length scale $\zeta$ is modeled as :

$$
\zeta^{*}=C_{\zeta}\left(\frac{\mu \varepsilon}{\kappa^{2}}\right)^{1 / 4}
$$


where $\varepsilon$ is the turbulence dissipation rate, $\kappa$ is the turbulent kinetic energy, $\mu$ is the laminar kinematic viscosity, and $C_{\zeta}$ is the volume-fraction constant. In addition, species are assumed to react in the fine structures over a time scale $\tau^{*}$ :

$$
\tau^{*}=C_{\tau}\left(\frac{\mu}{\varepsilon}\right)^{1 / 2}
$$

In the above equation $C_{\tau}$ is a time-scale constant. Consequently, reactions proceed over the time scale $\tau^{*}$ as :

$$
R_{i}=\frac{\rho\left(\zeta^{*}\right)^{3}}{\tau^{*}\left[1-\left(\zeta^{*}\right)^{3}\right]}\left(Y_{i}^{*}-Y_{i}\right)
$$

where $Y_{i}^{*}$ is the fine-scale mass fraction over time and length scales $\tau^{*}$, and $\zeta^{*}$, respectively. The fine-scales, where reaction occurs, ordinary differential equations are integrated numerically using the ISAT algorithm [17]. In addition, the dynamic cell clustering (DCC) is also used to reduce the computational time.

A mechanism of $\mathbf{7 1}$ species is reduced from the Model Fuel Library (MFL) [18] database to model low-temperature and high-temperature chemistry. Fig. 1 shows comparison between the final reduced mechanism and the Master MFL mechanism of 2545 species. The ignition delay and CO mass fraction matches those of the master mechanism.

\section{Flamelet Generated Manifold Combustion Model}

The FGM model $[13,14]$ is based on the laminar flamelet concept [7] that assumes the scalar evolution (that is the realized solution trajectories on the thermochemical manifold) in a turbulent flame as an ensemble of the scalar evolution of onedimensional (1D) laminar flamelets. The solution across such 1D flamelets is tabulated and further convoluted with a presumed probability density function to account for turbulence.

The flamelet tabulation approach can be summarized as follows: a set of laminar one-dimensional premixed or nonpremixed manifolds are solved. For spray configurations as the type simulated in the current work, non-premixed flamelets are found to outperform premixed flamelets, particularly in the predictions of $\mathrm{CO}$ and $\mathrm{H}_{2}$ mass fractions [20]. Here, opposed jet diffusion flamelets are utilized to generate the laminar manifolds.

For a constant pressure reacting mixture the laminar thermochemical state $\left(\Phi=\left[\mathrm{T}, \mathrm{y}_{\mathrm{i}}, \rho\right]\right)$ 1D profiles are solved across the flamelets domain. The flamelet domain boundary conditions represent the fuel and oxidizer streams, temperatures and mass fractions. Ambient oxidizer conditions are used to represent the reaction of pure oxidizer in Fuel. For non-premixed flamelets, the

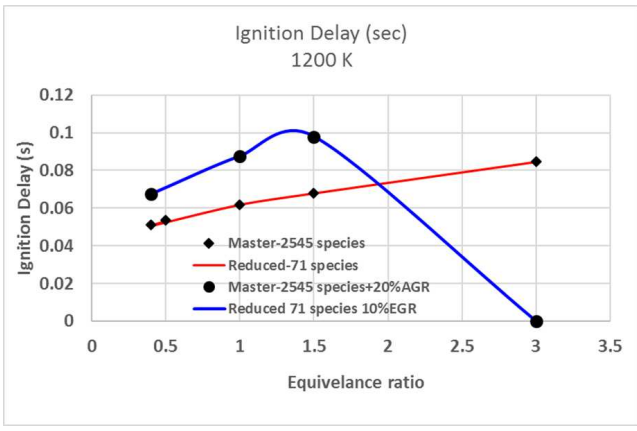

(a) Ignition delay

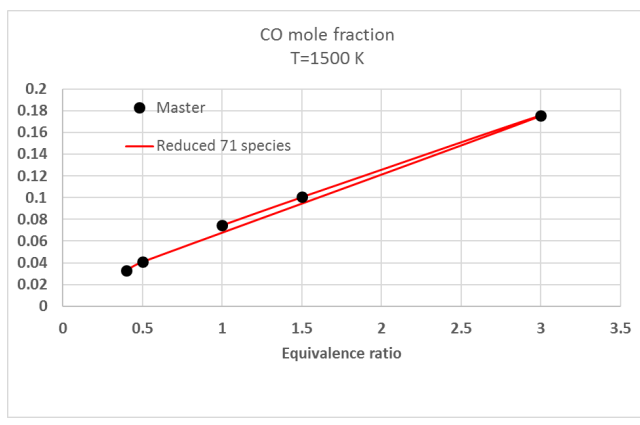

(b) CO mass fraction

FIGURE 1: Comparisons between the reduced (71 species) and the master (2545 species) mechanism ignition delay at and $\mathrm{CO}$ mass fraction.

1D flamelet equations are solved in the mixture fraction space $\mathrm{Z}$. The mixture fraction $\mathbf{Z}$ is defined using the Bilger formula [21]:

$$
\mathbf{Z}=\frac{\beta-\beta_{\mathbf{o x}}}{\beta_{\text {fuel }}-\beta_{\mathbf{o x}}},
$$

where $\beta=2 \frac{Y_{C}}{M_{w, c}}+0.5 \frac{Y_{H}}{M_{w, H}}-\frac{Y_{O}}{M_{w, O}}, Y_{C}, Y_{H}$, and $Y_{O}$ are the mass fractions of carbon, hydrogen, and oxygen atoms, and $M_{w, c}, M_{w, c}$, and $M_{w, c}$ are the molecular weights. $\beta_{o x}$ and $\beta_{\text {fuel }}$ are the values of the mass transfer $\beta$ at the oxidizer and fuel inlet streams.

The flamelet equations (i.e. energy and mass conservations) can be expressed in the following vector form in the $\mathbf{Z}$ space [7]:

$$
\rho \frac{\partial \Phi}{\partial t}-\rho \frac{\chi}{2} \frac{\partial^{2} \Phi}{\partial Z^{2}}=\dot{\omega}
$$

where $\rho$ is the mixture density, and $\dot{\omega}$ is the corresponding source-terms for the species and energy equations. The scalar dissipation rates $\chi$ is defined as [7]:

$$
\chi=2 D|\nabla Z|^{2} .
$$


For a unity Lewis number the scalar diffusivity $\mathbf{D}$ is equal to the thermal diffusivity. Each flamelet solves for the thermochemical state vector $\Phi=\left(\mathrm{T}, \mathrm{y}_{\mathrm{i}}, \rho\right)^{T}$ for the species mass fractions $\mathrm{y}_{\mathrm{i}}$, the temperature T, and the density $\rho$ for a given $\chi$ and initial fuel and oxidizer boundary conditions.

For non-premixed counterflow configuration flamelets, the scalar dissuasion rate $\chi$ is modeled as:

$$
\chi(Z)=\frac{\chi_{s t}}{4} \frac{3\left(\sqrt{\left(\rho / \rho_{\infty}\right)}+1\right)^{2}}{2 \sqrt{\left(\rho / \rho_{\infty}\right)}+1} \frac{\exp \left(-2\left[e r f c^{-1}(2 Z)\right]^{2}\right)}{\exp \left(-2\left[e r f c^{-1}\left(2 Z_{s t}\right)\right]^{2}\right)},
$$

where $\chi_{s t}$ and $Z_{s t}$ are the stoichiometric scalar dissipation rate and mixture fraction, respectively. And $\operatorname{erfc}^{-} 1$ is the inverse complementary error function. The stoichiometric scalar dissipation rate $\chi_{s t}$ is varied from $0.011 / \mathrm{s}$ until flamelet extinction at $\chi_{s t}=911 / \mathrm{s}$.

In FGM, $\Phi$ is parameterized by a mixture-fraction $\mathbf{Z}$, a reaction-progress variable $\mathbf{C}$, and a heat loss/gain parameter (or enthalpy) $\mathbf{H}$. The latter is used to account for the non-adiabatic effects. Parameterizing the solution with the progress variable instead of the scalar dissipation rate as in regular steady diffusion flamelets [7] allows the tables to access complete range of chemistry solutions from equilibrium to full extinction [20]. The reaction progress variable $\mathbf{C}$ is defined here as the sum of mass fractions of $\mathrm{CO}_{2}$ and $\mathrm{CO}$.

From the solved laminar manifolds the mixture fraction $\mathbf{Z}$, the progress variable $\mathbf{C}$, and the enthalpy $\mathbf{H}$, are computed by solving Eqs. 6 without the unsteady term. At a higher scalar dissipation rate, the flamelet will extinguish. For such a flamelet, the unsteady term is retained in Eqs. 6 and the flamelet domain is initialized by the last steady flamelet solution and then solved and tabulated until the mixing unburned solution is achieved.

To account for turbulence fluctuations the solution is convoluted with a Beta ( $\beta$ ) PDF distribution for both $\mathbf{Z}$ and $\mathbf{C}$, and with a delta function for $\mathbf{H}$. By using a delta function distribution for $\mathbf{H}$, the enthalpy fluctuations are assumed negligible. To further simplify the analysis, $\mathbf{Z}$ and $\mathbf{C}$ are assumed statistically independent variables. Consequently, the joint probability density function (PDF) between $\mathbf{Z}, \mathbf{C}$, and $\mathbf{H}$ can be expressed as $\mathrm{P}_{\mathrm{Z}, \mathrm{C}, \mathrm{H}}(\mathrm{z}, \mathrm{c}, \mathrm{h})=\mathrm{P}_{\mathrm{Z}}(\mathrm{z}) \mathrm{P}_{\mathrm{C}}(\mathrm{c}) \delta(\mathrm{h}-\overline{\mathrm{H}})$, where $\mathrm{P}_{\mathrm{Z}}(\mathrm{z})=\beta(z ; \widetilde{\mathbf{Z}}, \widetilde{\mathbf{Z}})$ and $\mathrm{P}_{C}(\mathrm{c})=\beta\left(c ; \widetilde{\mathbf{C}}, \widetilde{\mathbf{C}^{\prime \prime}}\right)$, and the small letters represent the stochastic variable. Finally, the mean thermochemical state solution $\bar{\Phi}$ can be computed for the density weighted PDFs:

$$
\begin{array}{r}
\bar{\Phi}\left(\widetilde{Z}, \widetilde{Z^{\prime \prime}}, \widetilde{C}, \widetilde{C^{\prime \prime}}, \widetilde{H}\right)= \\
\frac{\rho}{\bar{\rho}} \int_{0}^{1} \int_{0}^{1} \beta\left(z ; \widetilde{Z}, \widetilde{Z^{\prime \prime}}\right) \beta\left(c ; \widetilde{C}, \widetilde{C^{\prime \prime}}\right) \Phi(z, h, c) d z d c .
\end{array}
$$

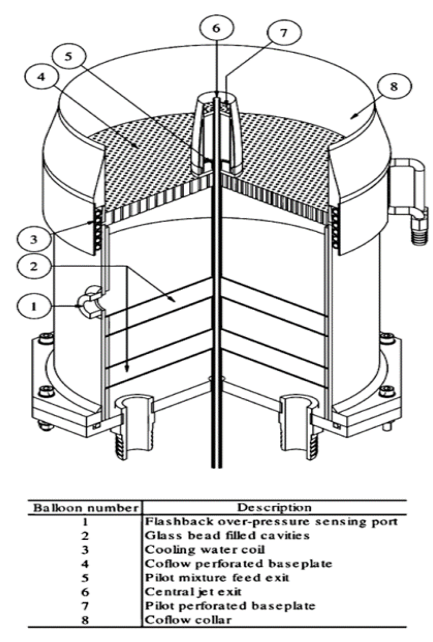

FIGURE 2: Experimental burner setup [9].

To simplify the tabulation and interpolation processes, the effect of $\widetilde{\mathbf{H}}$ on the mean species mass fractions is neglected, while the impact of the progress variable variance $\mathbf{C}$ " is neglected on the thermochemical properties like density and temperature. Consequently, the mean values for thermochemical state $\bar{\Phi}$ are then tabulated a priori in a lookup table as function of $\widetilde{\mathbf{Z}}, \widetilde{\mathbf{C}}, \mathbf{Z}$, and $\widetilde{\mathbf{H}}$ for the temperature $T$, the density $\rho$ and the specific heat $\mathrm{C}_{\mathrm{P}}$. While the mean mole fractions are tabulated as function of $\widetilde{\mathbf{Z}}, \widetilde{\mathbf{C}}, \mathbf{Z}$, and $\mathbf{C}$ ". Where $\widetilde{(~)}$ is the LES filtering. More details on the approach can be found in [10].

\section{Configuration and Numerical Setup}

The experimental setup is shown in Fig. 2. A schematic diagram for the corresponding computational setup is shown in Fig. 3. A lean mixture of methane/air is injected from the central tube with equivalence ratio of $\mathbf{0 . 5}$. To ignite the flame a co-flow mixture of stoichiometric premixed $\mathrm{CH}_{4}$ /air is injected through the central co-pilot. Another lean co-flow of premixed hydrogen/air mixture at $1500 \mathrm{~K}$ is injected around the pilot to shield the central jet combustion from the ambient air entrainment. For the equivalent non-reactive simulation, air at $298 \mathrm{~K}$ is injected through the pilot, the co-flow, and the central jet. The simulations are performed using ANSYS Fluent [19].

The conditions for the non-reactive flow simulations are summarized in Table 1. Where $\mathrm{V}_{\text {jet }}, \mathrm{T}_{\text {coflow }}, \mathrm{T}_{\text {pilot }}$, and $\mathrm{T}_{\text {jet }}$ are the central air jet velocity, the coflow temperature, pilot temperature and, central jet temperature, respectively. The reactive flow simulations conditions are shown in Table 2. Where $R e, R_{t}$, $\mathrm{Ka}$, and $\mathrm{Da}$ are the jet Reynolds number, the turbulent Reynolds number, the Karlovitz and the Damköhler number, respectively. 


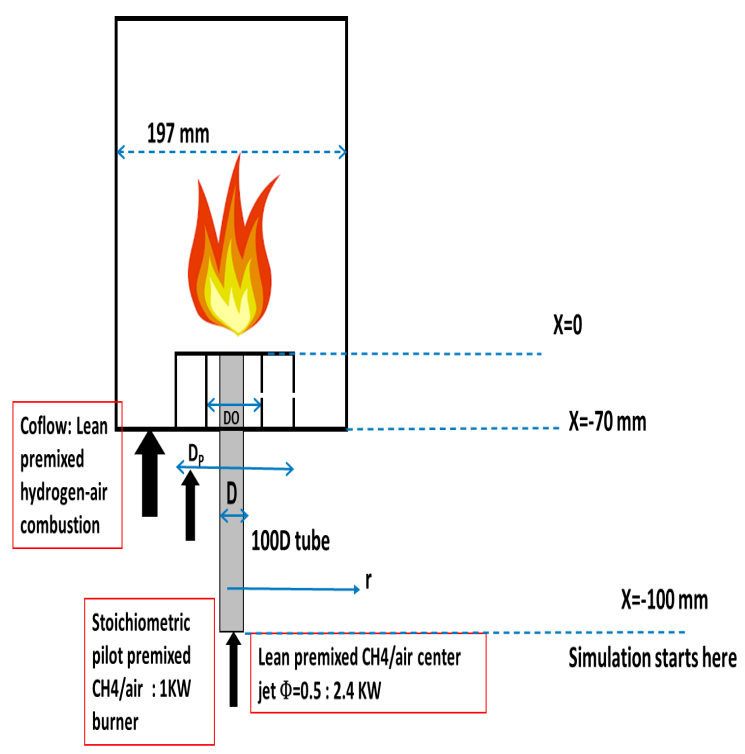

FIGURE 3: Schematic Diagram for burner setup and inflow conditions.

TABLE 1: Non-reactive flow conditions for the PPJB simulations

\begin{tabular}{rrrrrr} 
Case & Name & $\mathrm{V}_{\text {jet }}$ & $\mathrm{T}_{\text {coflow }}$ & $\mathrm{T}_{\text {pilot }}$ & $\mathrm{T}_{\text {jet }}$ \\
\hline 1 & $\mathrm{NR}-50-298$ & 50 & 298 & 298 & 298 \\
2 & $\mathrm{NR}-50-\mathrm{CF}-1500$ & 50 & 1500 & 1500 & 298 \\
3 & $\mathrm{NR}-100-298$ & 100 & 298 & 298 & 298 \\
4 & $\mathrm{NR}-150-298$ & 150 & 298 & 298 & 298 \\
5 & $\mathrm{NR}-150-\mathrm{CF}-1500$ & 150 & 1500 & 1500 & 298 \\
6 & $\mathrm{NR}-200-298$ & 200 & 298 & 298 & 298
\end{tabular}

The simulation setup is two-dimensional axi-symmetric with velocity inlet and pressure outlet boundary conditions. To achieve a realistic inflow conditions, the central inflow jet pipe is extended 100D upstream, where $\mathrm{D}=4 \mathrm{~mm}$ and is the nozzle diameter. The domain length is $100 \mathrm{D}$ upstream of the Nozzle outlet $(\mathrm{x}=0)$, and $120 \mathrm{D}$ downstream. The computational domain is shown in 4 . The coflow and pilot pipes are extended by $70 \mathrm{~mm}$ only. The impact of extending the coflow domain to $80 \mathrm{~mm}$ was found to be minor. The mesh count is 0.22 million hexahedral cells with s stretch rate of 1.2 a the nozzle exit. No strong sensitivity was shown by doubling he mesh count. Inside the inflow pipe, the first cell has $Y^{+}$range of 18-22.

A systematic study was performed to find the best turbulent inflow power-law profile. The inflow profile was found to have
TABLE 2: Reactive flow conditions for the PPJB simulations

\begin{tabular}{rrrrrrr} 
Case & Name & $\mathrm{V}_{\text {jet }}$ & $\mathrm{Re}$ & $\mathrm{Re}_{\mathrm{t}}$ & $\mathrm{Ka}$ & $\mathrm{Da}$ \\
\hline 1 & PM50 & 50 & 12500 & 720 & 100 & 0.069 \\
2 & PM100 & 100 & 25000 & 3100 & 1600 & 0.0089 \\
3 & PM150 & 150 & 37500 & 3700 & 2500 & 0.0063 \\
4 & PM200 & 200 & 50000 & 5200 & 3500 & 0.0053
\end{tabular}

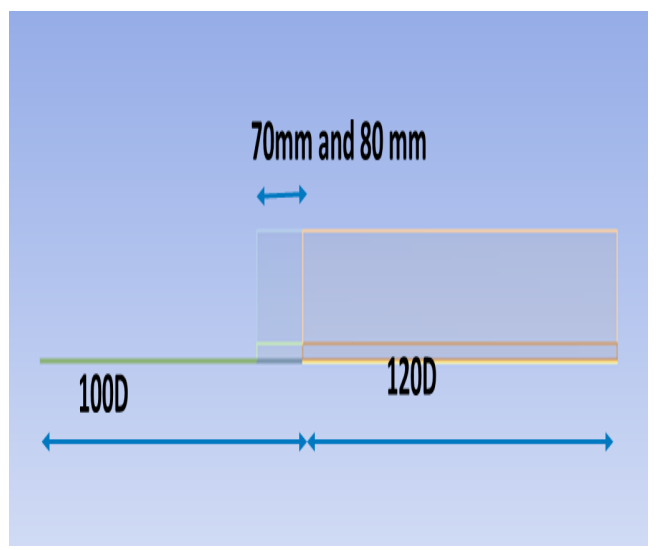

FIGURE 4: Computational domain.

an impact on the flow field downstream. As shown in Figs. 5, for the $50 \mathrm{~m} / \mathrm{sec}$ inflow case, the $1 / 6$ power law profile is closer to predictions for the inflow boundary layer thickness. For higher bulk velocities (i.e. $100,150,200 \mathrm{~m} / \mathrm{sec}$ ) the bulk velocity profiles or $1 / 18$ th power law are more appropriate for capturing the boundary-layer development and therefore it is recommended for high velocity inflow cases to use the $1 / 18$ th power-law profiles. The inflow velocity conditions are shown in Fig. 6.

Equilibrium composition for $\mathrm{H}_{2}$ /air mixture for an equivalence ratio of 0.43 is used for the hot co-flow reactive simulations. For the pilot, the maximum composition from the measurements at $\mathrm{x} / \mathrm{D}=2.5$ is used. Table 3 shows the inflow conditions for temperature and species for the PM-flames.

For turbulence, the SST-k- $\Omega$ model is used for closure. A coupled solver is used with second-order accurate convective terms and the least-square method for derivatives computation. More details on the numerical solver can be found in the ANSYS Fluent theory guide [19].

In the current paper all the non-reactive cases are reported as shown in Table 1. For the reactive flow results, only the PM150 test condition results are shown. In addition, a parametric study on the impact of modeling reaction length and time scales in EDC are shown. Table 4 shows the different EDC test cases re- 


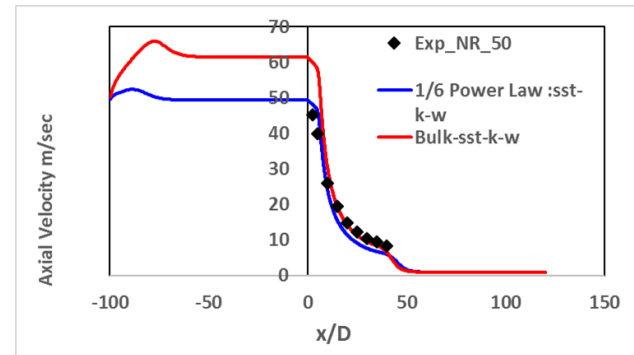

(a) NR-50-298

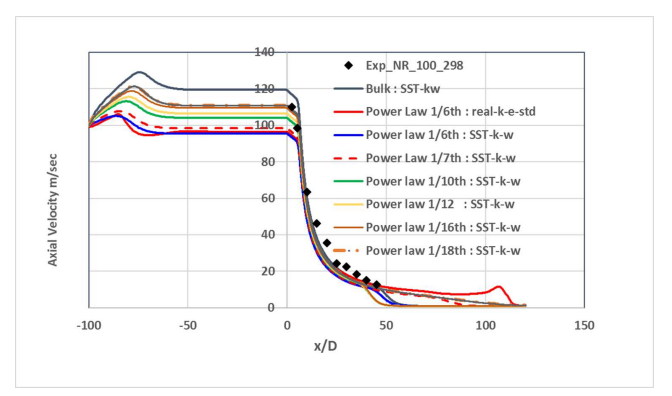

(b) NR-100-298

FIGURE 5: Impact of inflow velocity profile for NR-50-298 and NR-100-289 cases.

TABLE 3: Inflow conditions for the PPJB reactive flow simulations for the pilot and co-flow

\begin{tabular}{rrr} 
Name & Pilot & Co-flow \\
\hline $\mathrm{T}[\mathrm{k}]$ & 2236.4 & 1495.9 \\
$\mathrm{CH}_{4}$ & 0.00211 & - \\
$\mathrm{O}_{2}$ & 0.02052 & 0.13123 \\
$\mathrm{H}_{2}$ & 0.003552 & $6.664 \mathrm{e}-8$ \\
$\mathrm{OH}$ & 0.003708 & $5.373 \mathrm{E}-5$ \\
$\mathrm{H}_{2} \mathrm{O}$ & 0.1167 & 0.11136 \\
$\mathrm{CO}_{2}$ & 0.127 &
\end{tabular}

ported here.

\section{Results and Discussions}

We first discuss the nonreactive flow simulations, mesh resolution, and turbulence model selection. Then the reactive flow simulation for the PM150 case are shown in section using the EDC and the FGM model.

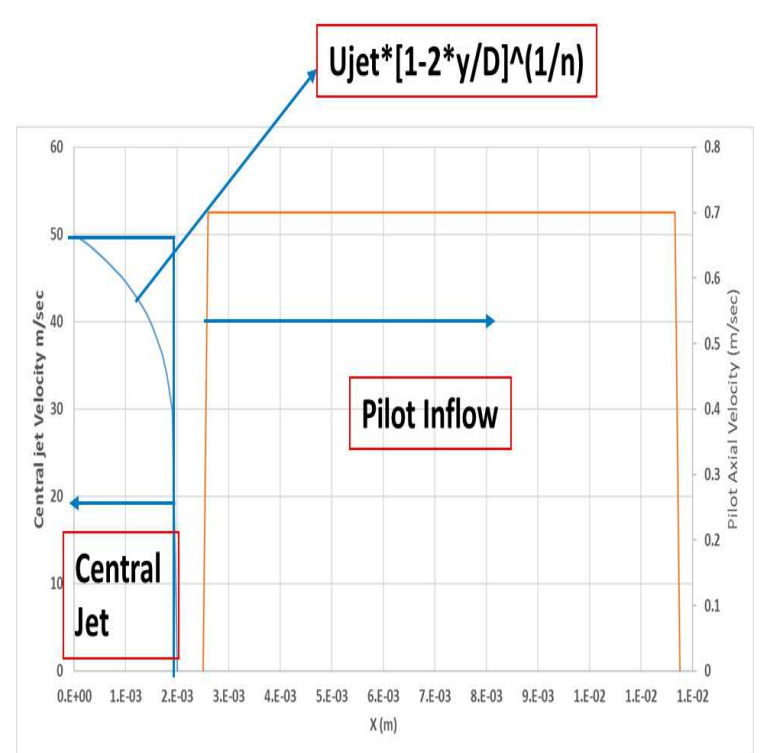

FIGURE 6: Inflow profiles to the burner.

TABLE 4: Reactive flow conditions for the PPJB simulations

\begin{tabular}{rrrr} 
Case & Name & $C_{\zeta}$ in Eq. 2 & $C_{\tau}$ in Eq. 3 \\
\hline 1 & EDC-2-0.4 & 2.1377 & 0.4082 \\
2 & EDC-2-0.04 & 2.1377 & 0.04082 \\
3 & EDC-0.2-0.4 & 0.21377 & 0.4082 \\
4 & EDC-0.2-0.04 & 0.21377 & 0.04082
\end{tabular}

\section{Nonreactive Flow Simulations}

Figure 7, show the centerline velocity, centerline turbulent kinetic energy, and the velocity distribution at two radial locations $x / D=5$ and $x / D=15$. Different mesh resolutions of 0.22 million cells and 0.9 million cells are compared. In addition, the realizable k- $\varepsilon$ model and the SST-k- $\omega$ model are compared for the smaller-size mesh. The results show that the realizable k$\varepsilon$ model under-predicts the centerline turbulence kinetic energy, while the SST-k- $\omega$ model over-predicts the centerline velocity. Overall, the two models showed very similar results, except for the TKE, where the SST-k- $\omega$ model matched the profile. The results were also insensitive to grid refinement. Based on these results a 0.5 millon cells and the SST-k- $\omega$ model were chosen as the working mesh and turbulence closure model in all the following simulations.

Figures 8, 9, 10, 11, and 12 show comparisons with the measurements for NR-50-1500, NR-100-298, NR-150-298, NR150-1500, NR-200-298 cases, respectively. Good centerline data 


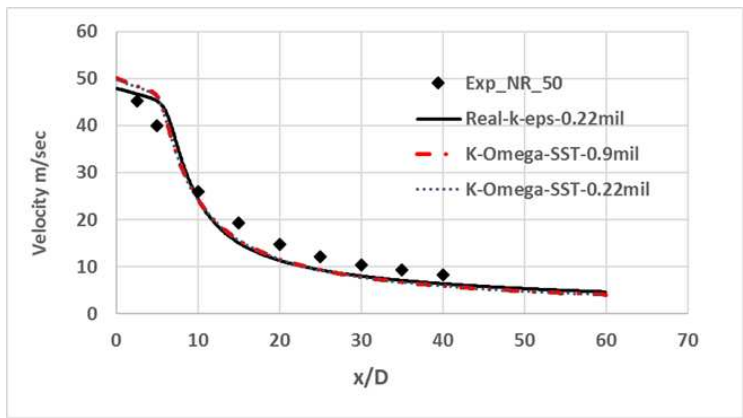

(a) Centerline $\mathrm{U} m / \mathrm{s}$

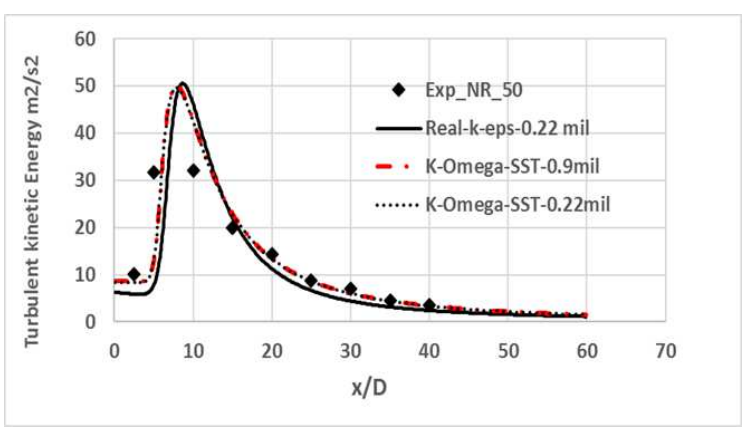

(b) Centerline TKE $m^{2} / s^{2}$

FIGURE 7: Comparison of axial velocity $U$ and turbulent kinetic energy (TKE) for NR-50-298 case with measurements with different mesh resolutions and turbulence models.

match are seen for all non-reactive jets. The centerline velocity for NR-50-1500, where the co-flow is heated to 1500 , shows under-prediction of the centerline velocity with a good spread rate in the radial direction. The NR-100-298 shows overprediction of the peak centerline TKE and over-prediction of the velocity field in the radial direction. The radial profiles deviate most for NR-100-298. In-addition, the profiles at the farthest available downstream location show the most deviation from measurements. Refining at these locations did not change the results. An excellent match is shown for NR-150-298 case. The centerline TKE was also over-predicted for the NR-150-1500 and NR-100-298, with good centerline match otherwise.

\section{Reactive Flow Simulations}

In the current work we focus on the PM150 test case. This case falls in regime $C$ in the stability diagram shown in Fig. 13. This regime is characterized by a neck structure close to the pilot followed by extinction at $\mathrm{x} / \mathrm{D}=25$ and re-ignition further downstream. The flame $\mathrm{CH}^{*}$ luminosity time-averaged over $2 \mathrm{~s}$ is shown in Fig. 14. The PM150 flame showed reduction in luminosity between $x / D=12-x / D=20$ and an increase in luminosity in the re-ignition zone around $\mathrm{x} / \mathrm{D}=40$. The target of the current

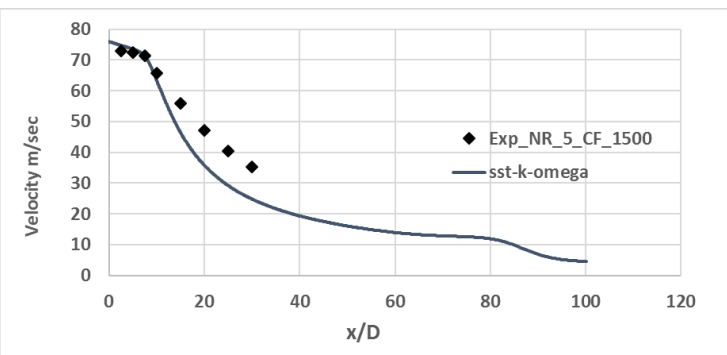

(a) Centerline $\mathrm{U} m / \mathrm{s}$

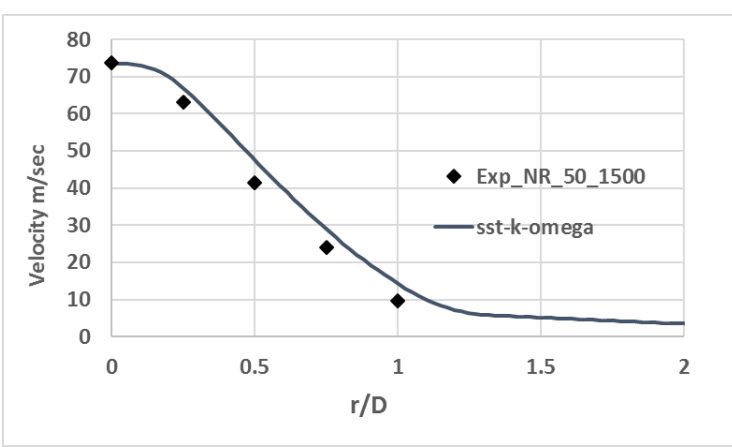

(b) $x / D=5$

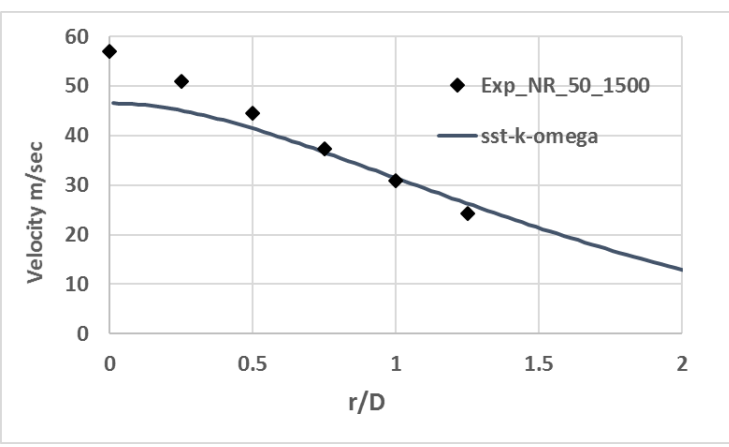

(c) $x / D=15$

FIGURE 8: Comparison of velocity $U$ and turbulent kinetic energy (TKE) for NR-50-1500 case with measurements.

work is to examine the model's ability to capture such events.

First we compare the middle plane temperature distribution between FGM and EDC models. As the PPJB setup has hydrogen/air mixture injected at the coflow section, ideally this setup needs a three stream tabulation, where the two mixture fractions can be defined, one for the co-flow and another for the pilot and the central jet injection. Two simulations are performed for FGM, one with a two-streams formulation, where the hydrogen/air mixture is approximated by a $\mathrm{CH}_{4}$ /air mixture with the equivalence ratio to produce the same co-flow temperature of $1500 \mathrm{~K}$. The second FGM setup named FGM-inert, uses an inert stream to substitute the $\mathrm{H}_{2}$ /air co-flow stream. In the inert formu- 


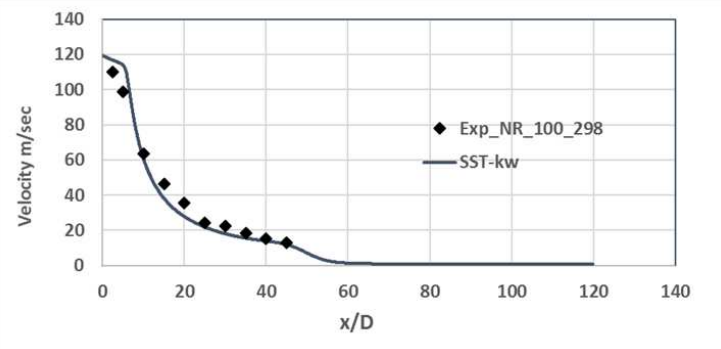

(a) Centerline $\mathrm{U} \mathrm{m} / \mathrm{s}$

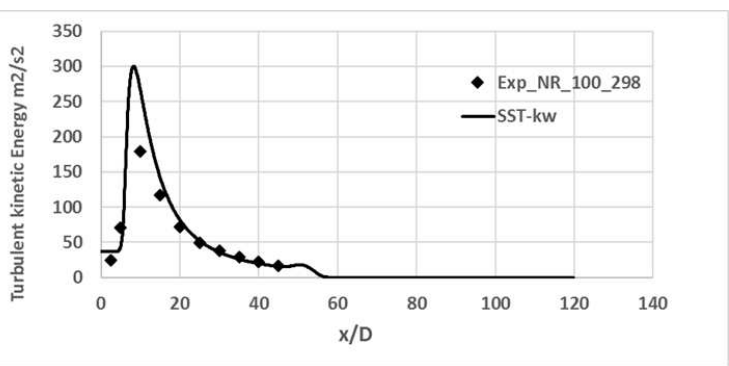

(b) Centerline TKE $\mathrm{m}^{2} / \mathrm{s}^{2}$

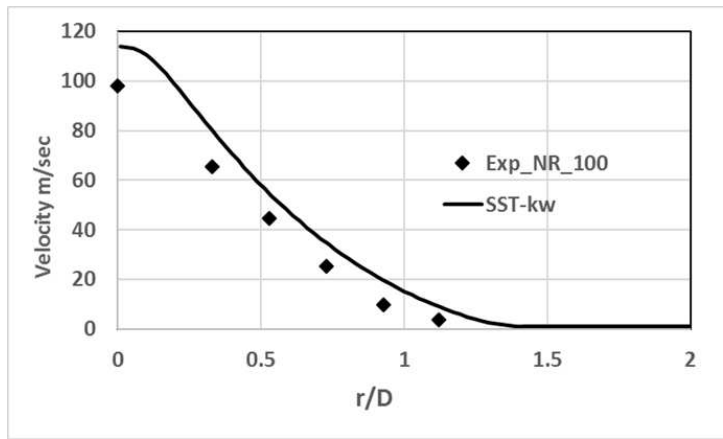

(c) $\mathrm{x} / \mathrm{D}=5$

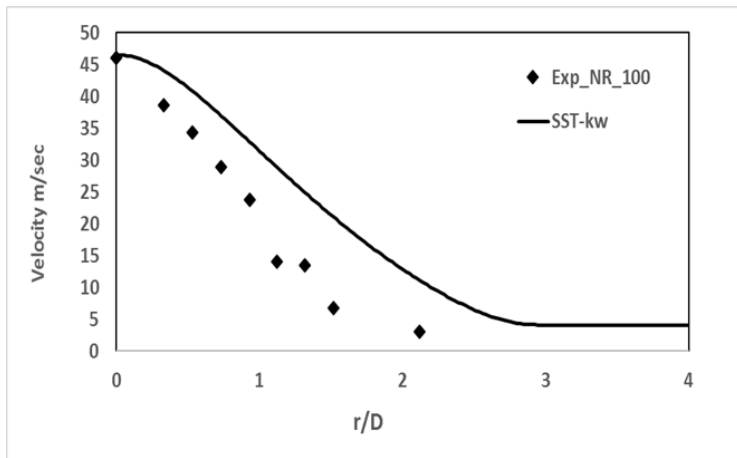

(d) $\mathrm{x} / \mathrm{D}=15$

FIGURE 9: Comparison of axial velocity $\mathrm{U}$ and turbulent kinetic energy (TKE) for NR-100-298 case with measurements.

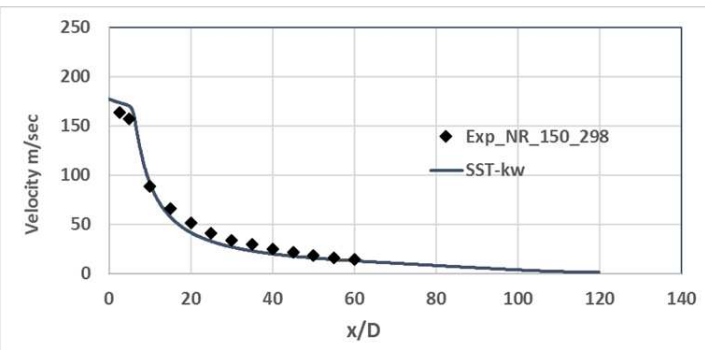

(a) Centerline $\mathrm{U} \mathrm{m} / \mathrm{s}$

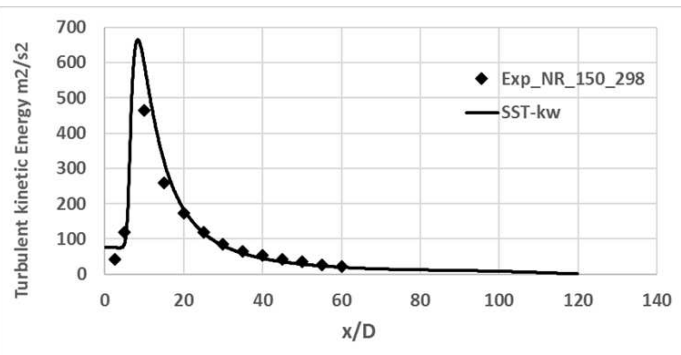

(b) Centerline TKE $m^{2} / s^{2}$

FIGURE 10: Comparison of axial velocity $\mathrm{U}$ and turbulent kinetic energy (TKE) for NR-150-298 case with measurements.

lation an extra equation is solved for the inert mass fraction and the density and enthalpy are weighted to account for the mixing effect with the inert stream. The two simulations steady-state, mean temperature distribution are compared with the EDC models with different fine scales as in Table 4 and shown in Fig. 15. The FGM model shows higher flame temperature which affects predictions of the major species such as $\mathrm{CO}$ and $\mathrm{CO}_{2}$. That happened as injection at the co-flow section is for $\mathrm{CH}_{4}$ fuel rather than $\mathrm{H}_{2}$ fuel. That also increases the reactivity due to the excess fuel added and increases the peak temperature at the centerline as the coflow gets entrained towards. With the inert, model however, the temperature distribution is similar to the EDC model with the smaller fine time scale case EDC-0.2-0.4.

The centerline mean temperature, $\mathrm{CO}_{2}, \mathrm{CO}$ and $\mathrm{OH}$ mass fractions are compared with the measurements in Figs. 16, 17, 18 and 19, respectively. As expected FGM with a single fuel (i.e two stream formulation) over-predicts the temperature, while with the inert model the centerline temperature seems to be captured well. For EDC the impact of the reaction source term integration fine time scale is found to have more strong impact than the length scale. With smaller integration time scale the EDC model was able to capture the flame structure more accurately. The impact of the reaction fine length scale is less prominent.

For the major species, FGM was found to over-predict $\mathrm{CO}$ and $\mathrm{CO}_{2}$ and under-predicts the $\mathrm{OH}$ mass fraction. Neither FGM or FGM-inert captured the re-ignition far downstream. The FGM 


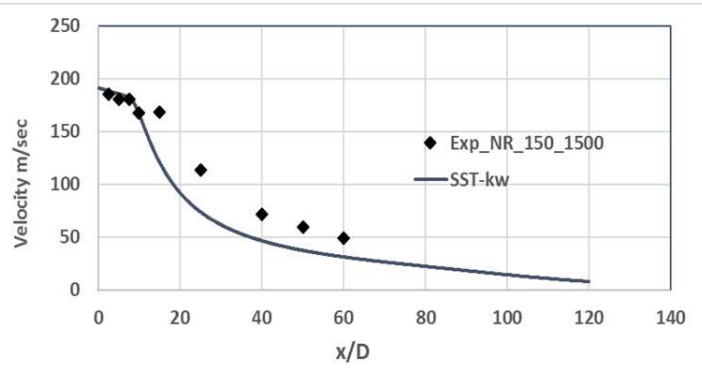

(a) Centerline $\mathrm{U} \mathrm{m} / \mathrm{s}$

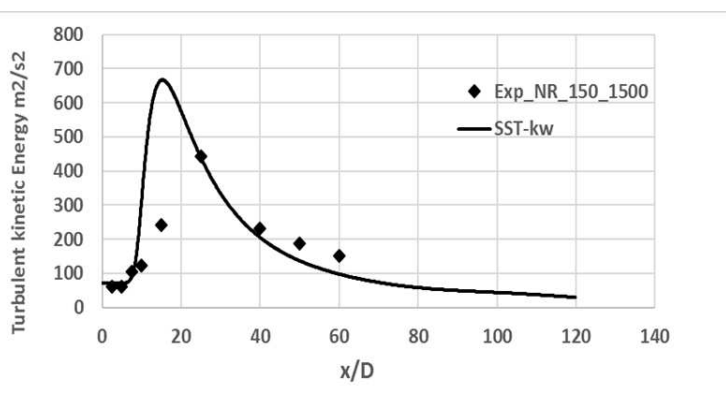

(b) Centerline TKE $m^{2} / s^{2}$

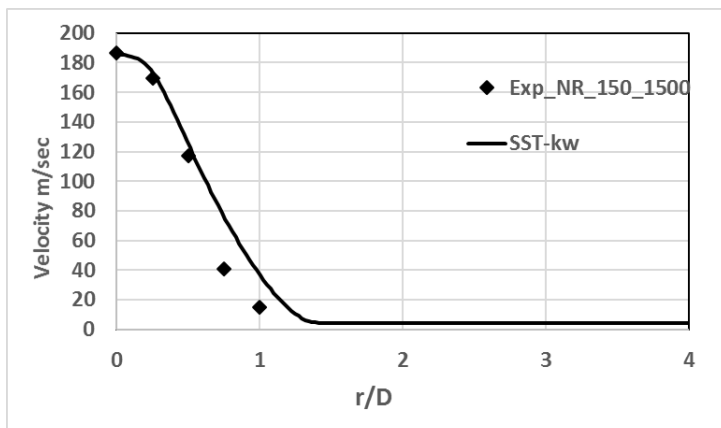

(c) $x / D=5$

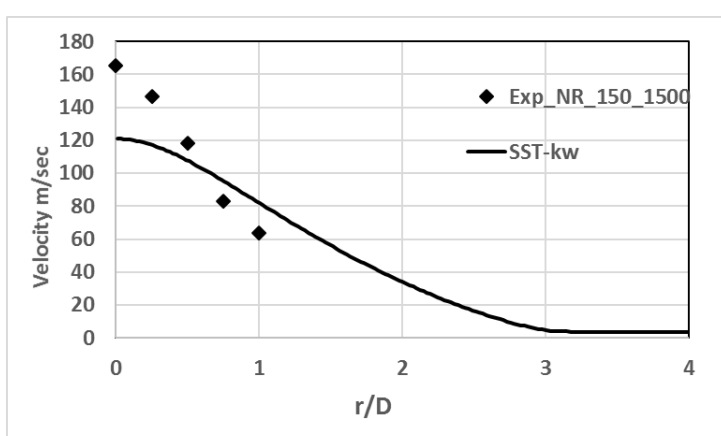

(d) $x / D=15$

FIGURE 11: Comparison of velocity $U$ and turbulent kinetic energy (TKE) for NR-150-1500 case with measurements.

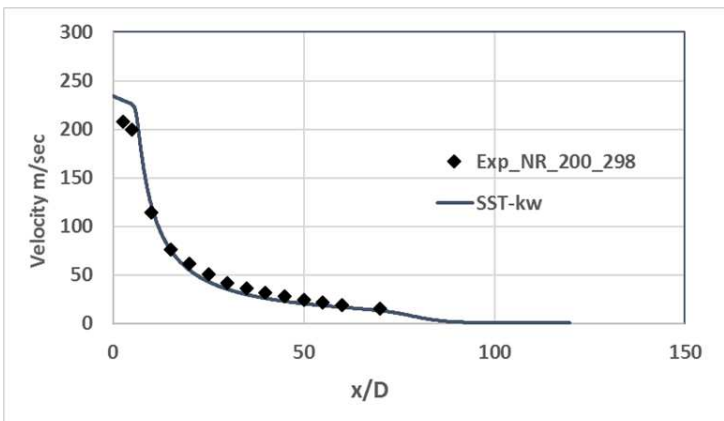

(a) Centerline $\mathrm{U} m / \mathrm{s}$

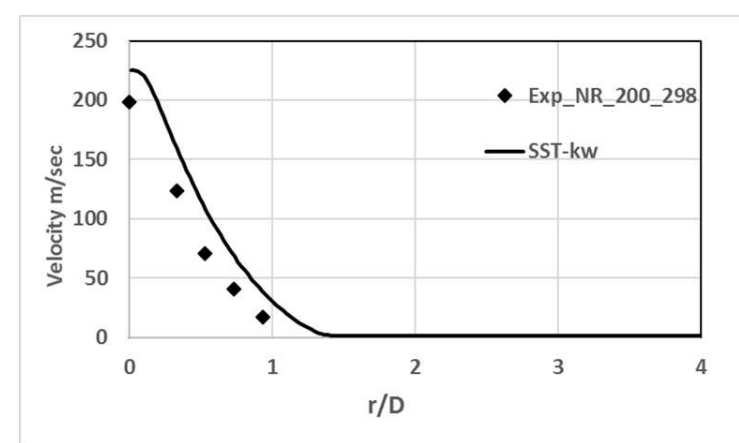

(b) $x / D=5$

FIGURE 12: Comparison of velocity $U$ and turbulent kinetic energy (TKE) for NR-200-298 case with measurements.

with inert stream is found to reduce the reactivity significantly and therefore no further data for this setup is shown. In addition, reactivity was delayed further downstream for FGM as well as the EDC model with the larger reaction integration time scale. Similar to measurements, the $\mathrm{OH}$ trend for the EDC cases with the smaller time scale (i.e. EDC-0.2-0.4 and EDC-0.2-0.04) was found to increase further downstream, which indicates possible re-ignition as expected for this type of flame. In general the EDC cases with time scale factor of 0.2 were found to capture the trend measurements more closely and better than with the larger time scale.

To further understand the impact of fine time scale factor on the flame structure, Fig. 20 show the $\mathrm{OH}$ mass fraction middle plane distribution for the EDC-0.2-0.4 and the EDC-2-0.4 for PM150 flame. Both flames show a necking behavior downstream of the nozzle around $x / D=10$. However, the EDC-0.2-0.4 shows a region in-between $x / D=10$ and $x / D=30$ where $O H$ is reduced significantly. This region is followed by another region $\mathrm{x} / \mathrm{D}>30$ where $\mathrm{OH}$ increases similar to a re-ignition behavior. Such reignition seems to occur radially first at $\mathrm{x} / \mathrm{D}=30$ rather than at the centerline location. The FGM shows a shorter and more compact flame structure. The corresponding centerline $\mathrm{OH}$ net chemical rates are shown in 21. The EDC-0.2-0.04 has a higher consump- 


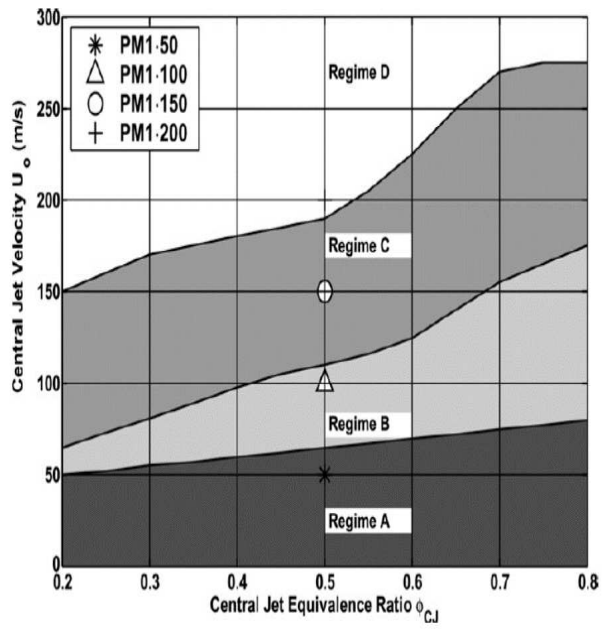

FIGURE 13: Stability Diagram [9].

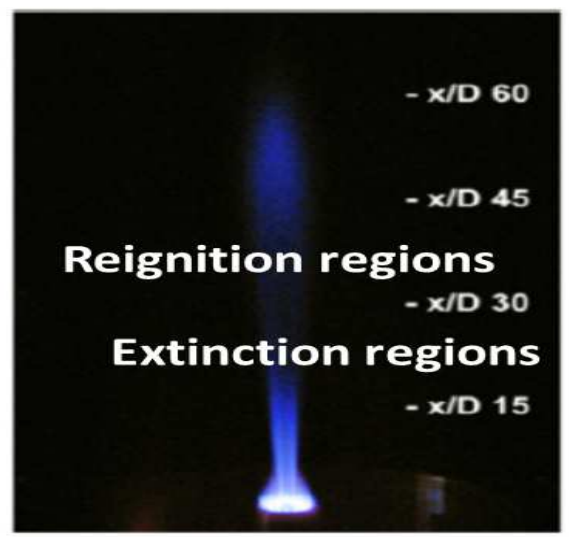

PM150

FIGURE 14: $C H^{*}$ Experimental Luminosity for PM1-150 flame [9].

tion rate of $\mathrm{OH}$ at the centerline, which leads to the low luminosity region observed in experiments.

For completeness the equivalent temperature radial profiles at $x / D=2.5, x / D=15$, and $x / D=30$ are shown in Fig. 22, respectively. $\mathrm{Ar} x / \mathrm{D}=2.5$ downstream of the nozzle outlet, all models showed good behavior and captured the flame front correctly. At $\mathrm{x} / \mathrm{D}=15, \mathrm{FGM}$ overall over-predicts the temperature, while all models over-predict the centerline, EDC-0.2-0.04 and EDC-0.2-0.4 showed the best match with the temperature profile. At $\mathrm{x} / \mathrm{D}=30$, EDC-0.2-0.04 and EDC-0.2-0.4 match pretty well with the measurements, while FGM, EDC-2-0.04 and EDC=20.4 over-predicts the temperature globally.

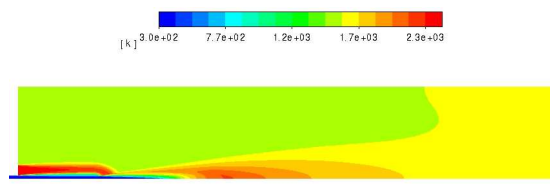

(a) FGM-two-streams

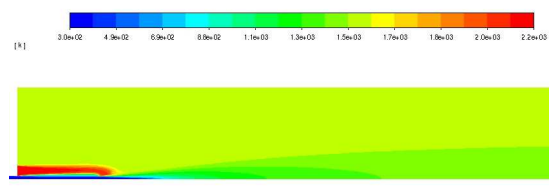

(b) FGM with inert stream

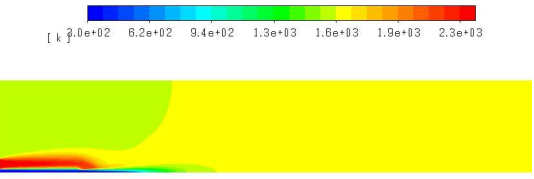

(c) EDC-2-0.4

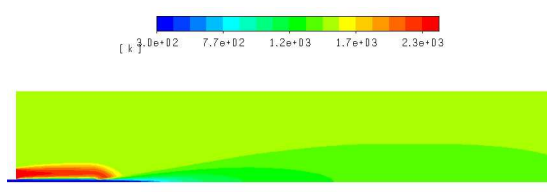

(d) EDC-0.2-0.4

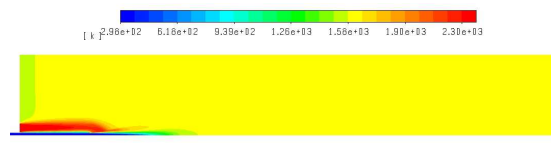

(e) EDC-2-0.04

FIGURE 15: Steady state temperature distribution for PM1-150 case. The EDC cases are described in Table. 4

\section{Conclusions}

In the current work steady-state simulations for the piloted premixed jet burner (PPJB) [11] are performed. The measurements are used to assess the FGM and EDC models to predict high finite rate and turbulence/chemistry interaction effects under low Damköhler number. A parametric study is performed for different power law turbulent inflow profiles. The sensitivity of the results to the inflow profiles is evident. Overall a good match with the experimental data is observed for the nonreactive flow cases with general under-prediction for the turbulent kinetic energy (TKE). The reactive flow results show that steady-state simulation was able to capture the necking behavior for the PM150 flame. For PM150 flame presented here, the FGM showed reasonable comparison with temperature, with over-prediction of the peak, under-prediction for $\mathrm{OH}$ mass frac- 


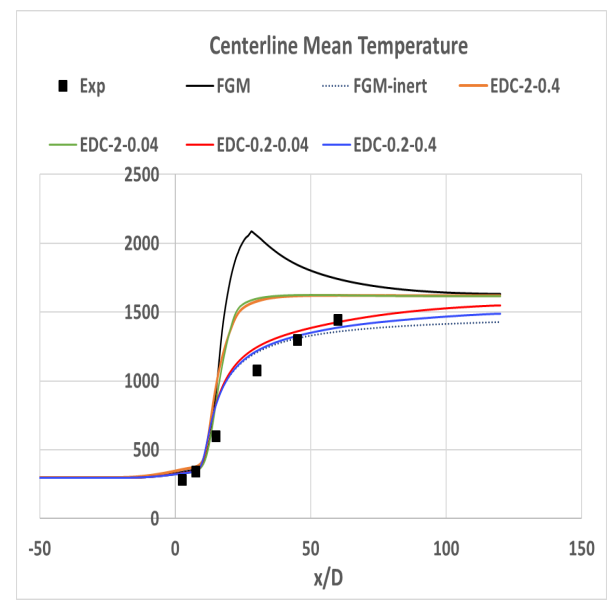

FIGURE 16: Mean centerline temperature distribution for PM1150 flame.

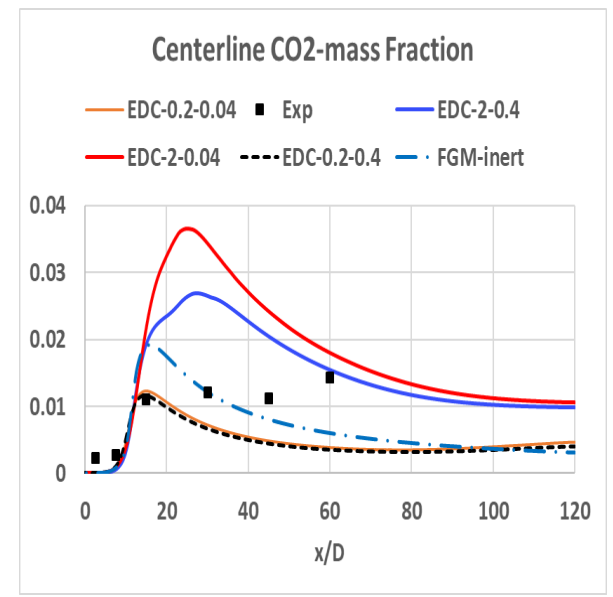

FIGURE 17: Mean centerline $\mathrm{CO}_{2}$ mass fraction distribution for PM1-150 flame.

tion and over-prediction for the major species. The EDC model was able to capture flame extinction and re-ignition downstream for the nozzle with the correct fine time scales. The current study shows the importance of finite rate chemistry modeling for low Damköhler number flows.

\section{REFERENCES}

[1] Lefebvre, A. H., 1999. Gas Turbine Combustion, second ed. Taylor \& Francis, London, UK.

[2] Dhanuka, S., Driscoll, J. F., Temme, H., and Mongia, H., 2008. "Vortex shedding and mixing layer ffects on periodic flashback in a lean premixed prevaporized gas turbine

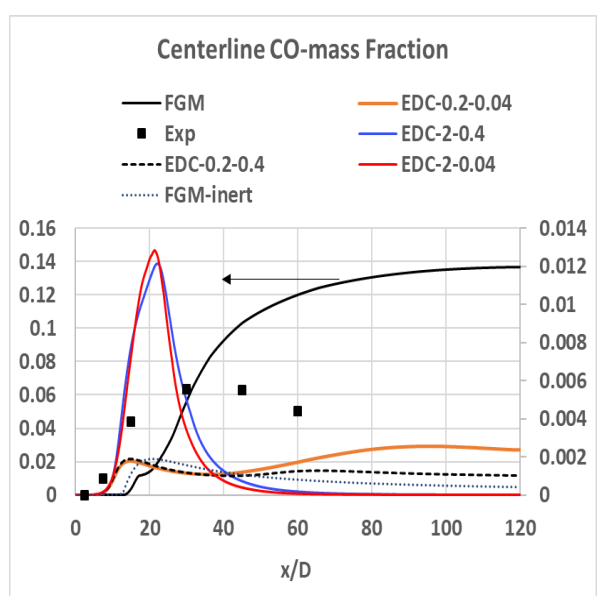

FIGURE 18: Mean centerline $C O$ mass fraction distribution for PM1-150 flame.

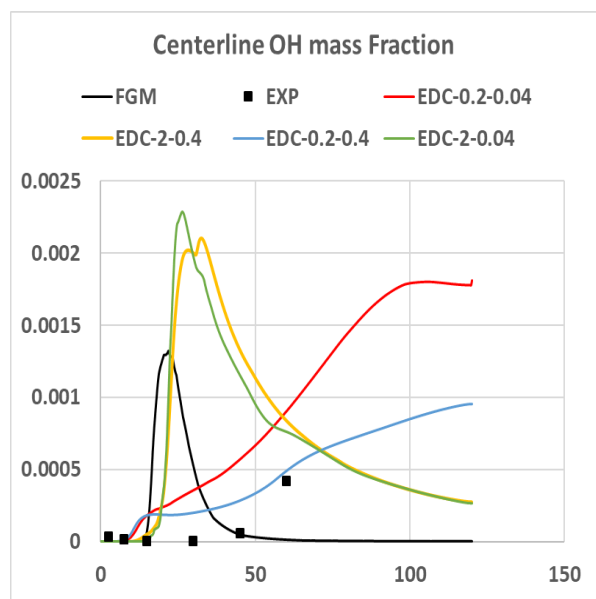

FIGURE 19: Mean centerline $\mathrm{OH}$ mass fraction distribution for PM1-150 flame.

combustor”. Proc. Combust. Inst., 32, pp. 2901-2908.

[3] Menon, S.“, 2005.”. In Combustion Instabilities in Gas Turbine Engines: Operational Experience, Fundamental Mechanisms, and Modeling, vol. 210, T. Lieuwen and V. Yang, eds. AIAA Progress in Aeronautics and Astronautics, pp. $277-314$.

[4] EPA, 2018. Environmental protection agency report : Stationary combustion turbines: National emission standards for hazardous air pollutants (NESHAP). https://www.epa.gov/stationary-sourcesair-pollution/stationary-combustion-turbines-nationalemission-standards.

[5] El-Asrag, H., and Li, S., 2018. "Investigation of extinction 


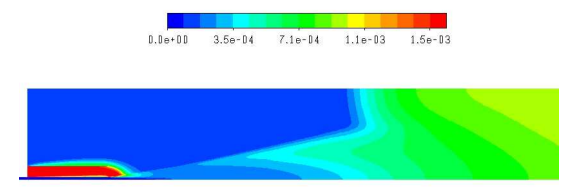

(a) EDC-0.2-0.4

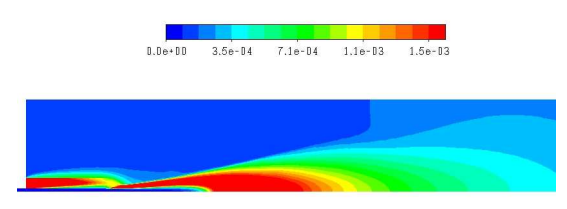

(b) EDC-2-0.4

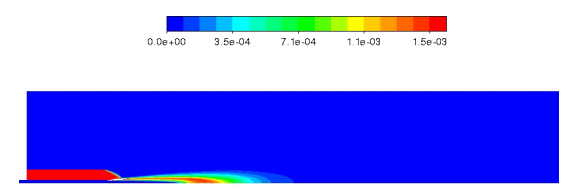

(c) FGM

FIGURE 20: Steady state OH mass fraction distribution for PM1150 case. The EDC cases are described in Table. 4

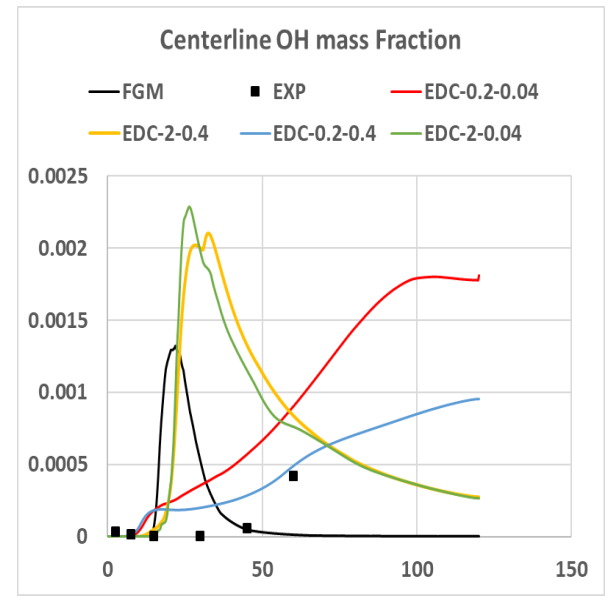

FIGURE 21: Mean centerline $\mathrm{OH}$ mass fraction distribution for PM1-150 flame.

and reignition events using the flamelet generated manifold model”. IGTI-18-75420, June 11-15, Lillestrøm, Norway.

[6] Dunn, M. A., Masri, A. R., and Bilger, R. W., 2007. "A new piloted premixed jet burner to study strong finite-rate chemistry effects". Combusiton and Flame, 151, pp. 4660.

[7] Peters, N., 2000. Turbulent Combustion. Cambridge University Press, Cambridge, UK.

[8] Pitsch, H., 2006. "Large-eddy simulation of turbulent com-

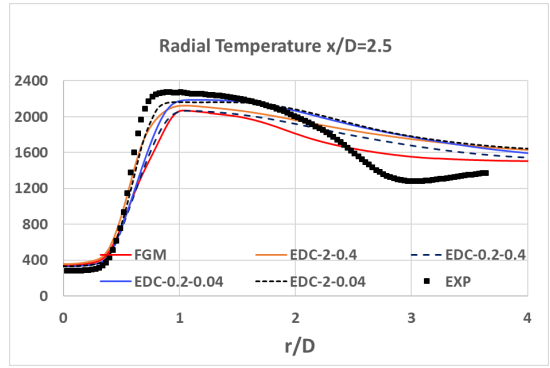

(a) $x / D=2.5$

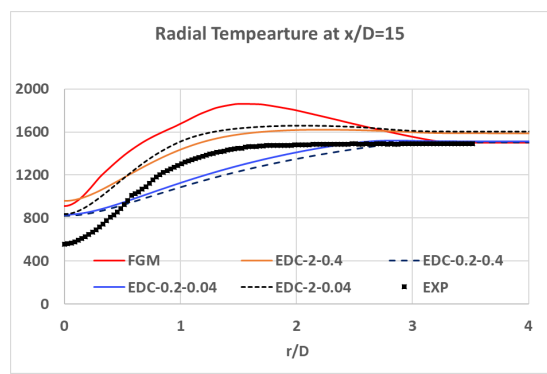

(b) $x / D=15$

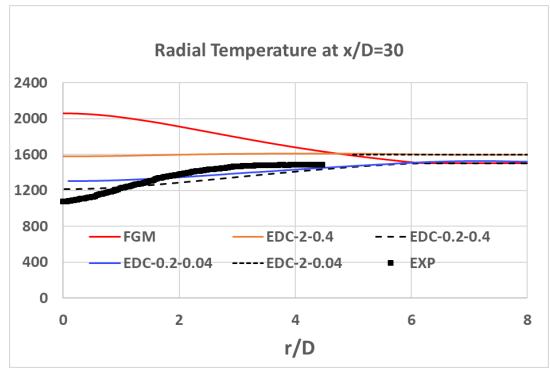

(c) $\mathrm{x} / \mathrm{D}=30$

FIGURE 22: Steady state mean temperature radial profiles for PM1-150 case. The EDC cases are described in Table. 4

bustion". Аnпи. Rev. Fluid Mech., 38, pp. 233-266.

[9] Dunn, M. A., Masri, A. R., Bilger, R. W., and Barlow, R. S., 2010. "Finite rate chemistry effects in highly sheared turbulent premixed flames". Flow Turbulence and Combustion, 85, pp. 621-648.

[10] ElAsrag, H., Braun, M., and Masri, A., 2016. "Large eddy simulations of partially premixed ethanol dilute spray flames using the flamelet generated manifold model". Combustion Theory and Modeling, 20(4), pp. 567-591.

[11] Chen, Y., and Ihme, M., 2013. "Large-eddy simulation of a piloted premixed jet burner". Combusiton and Flame, 160, pp. 2896-2910.

[12] Pierce, C. D., and Moin, P., 2004. "Progress-variable approach for large-eddy simulation of non-premixed flames.". J. Fluid Mech., 504, pp. 73-97.

[13] Ramaekers, W. J. S., Oijen, J. A., and De Goey, L. P. H., 
2010. "A priori testing of flamelet generated manifolds for turbulent partially premixed methane/air flames". Flow Turb. Combust., 84, pp. 439-458.

[14] Van Oijen, A. J., and De Goey, L. H. P., 2000. "Modelling of premixed laminar flames using flamelet-generated manifolds". Combust. Sci. Tech., 84, pp. 439-458.

[15] Rowinski, D. H., and Pope, S. B., 2011. "Pdf calculations of piloted premixed jet flames". Combusiton Theory and Modeling, 15, pp. 245-266.

[16] Magnussen, B. F., 1981. "On the structure of turbulence and a generalized eddy dissipation concept for chemical reaction in turbulent flow". Nineteenth AIAA Meeting, St. Louis.

[17] Pope, S., 1997. "Computationally efficient implementation of combustion chemistry using in-situ adaptive tabulation". Combusiton Theory and Modeling, 1, pp. 41-63.

[18] ANSYS, 2017. Model fuel library. http://www.ansys.com/products/fluids/ansys-modelfuel-library.

[19] ANSYS-Fluent-2019R1, 2019. ANSYS-Fluent Theory Manual. http://www.ansys.com/.

[20] Vreman, A. W., Albrecht, B., Van Oijen, A. J., De Goey, L. H. P., and Bastiaans, R. J. M., 2008. "Premixed and nonpremixed generated manifolds in large-eddy simulation of sandia flame d and f.". Combust. Flame, 153, pp. 394-416.

[21] Bilger, R. W., and Starner, S. H., 1990. "On reduced mechanisms for methane/air combustion in nonpremixed flames.". Combust. Flame, 80(2), pp. 135-149.

\section{List of Tables}

1 Non-reactive flow conditions for the PPJB simulations ................. 5

2 Reactive flow conditions for the PPJB simulations 5

3 Inflow conditions for the PPJB reactive flow simulations for the pilot and co-flow . . . . . . . 6

4 Reactive flow conditions for the PPJB simulations 6 


\section{List of Figures}

1 Comparisons between the reduced (71 species) and the master (2545 species) mechanism ignition delay at and $\mathrm{CO}$ mass fraction. . . . . . . 3

2 Experimental burner setup [9]. . . . . . . . . . . 4

3 Schematic Diagram for burner setup and inflow conditions. . . ........... 5

4 Computational domain. . . . . . . . . . . 5

5 Impact of inflow velocity profile for NR-50-298 and NR-100-289 cases. . . . . . . . . . . . . 6

6 Inflow profiles to the burner. . . . . . . . . . 6

7 Comparison of axial velocity $U$ and turbulent kinetic energy (TKE) for NR-50-298 case with measurements with different mesh resolutions and turbulence models. . . . . . . . . . . . 7

8 Comparison of velocity $U$ and turbulent kinetic energy (TKE) for NR-50-1500 case with measurements. . . . . . . . . . . . . . .

9 Comparison of axial velocity $\mathrm{U}$ and turbulent kinetic energy (TKE) for NR-100-298 case with measurements. . . . . . . . . . . . .

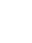
4 5 5

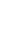

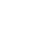

10 Comparison of axial velocity $U$ and turbulent kinetic energy (TKE) for NR-150-298 case with measurements. . . . . . . . . . . 8

11 Comparison of velocity $U$ and turbulent kinetic energy (TKE) for NR-150-1500 case with measurements. . . . . . . . . . . . . .

12 Comparison of velocity $\mathrm{U}$ and turbulent kinetic energy (TKE) for NR-200-298 case with measurements. . . . . . . . . . . . . . . 9

13 Stability Diagram [9]. . . . . . . . . . . . . 10

$14 \mathrm{CH}^{*}$ Experimental Luminosity for PM1-150 flame [9]. . . . . . . . . . . . . . . . . . 10

15 Steady state temperature distribution for PM1150 case. The EDC cases are described in Table. ?? 10

16 Mean centerline temperature distribution for PM1-150 flame. . . . . . . . . . . . . . 11

17 Mean centerline $\mathrm{CO}_{2}$ mass fraction distribution for PM1-150 flame. . . . . . . . . . . . . . 11

18 Mean centerline $C O$ mass fraction distribution for PM1-150 flame. . . . . . . . . . . . . . 11

19 Mean centerline $\mathrm{OH}$ mass fraction distribution for PM1-150 flame. . . . . . . . . . . . . . . . 11

20 Steady state $\mathrm{OH}$ mass fraction distribution for PM1-150 case. The EDC cases are described in Table. ?? . . . . . . . . . . . . . . . 12

21 Mean centerline $\mathrm{OH}$ mass fraction distribution for PM1-150 flame. . . . . . . . . . . . . . . . 12

22 Steady state mean temperature radial profiles for PM1-150 case. The EDC cases are described in Table. ?? . . . . . . . . . . . . . . . . . 12 